Journal of Case Reports 2018;8(2):144-146

\title{
Parietolith after Laparoscopic Cholecystectomy Presenting with Discharging Sinus: An Avoidable Morbidity
}

\author{
Arshad Hasan, Vinod Kumar \\ Department of General Surgery, All India Institute of Medical Sciences, Patna, Bihar, India.
}

\author{
Corresponding Author: \\ Dr. Arshad Hasan \\ Email: arshadsurgery@gmail.com \\ This is an Open Access article distributed \\ under the terms of the Creative Commons \\ Attribution License (creativecommons.org/ \\ licenses/by/3.0). \\ Received : January 10,2018 \\ Accepted : April 9,2018 \\ Published : June 5, 2018
}

\begin{abstract}
Background: Spillage of gallstone is uncommon during laparoscopic cholecystectomy. Spillage in inflamed and friable gallbladder can occur during dissection of gallbladder from liver bed, injury to the gallbladder wall from grasping forceps and during removal of gallbladder from port site. The spilled stone in abdominal wall may cause abscess and sinus formation. Case Report: We treated a case of 52 year male presenting with discharging sinus from epigastric port site after laparoscopic cholecystectomy. Conclusion: High index of suspicion should be maintained for spillage in a patient presenting with port site sinus after laparoscopic cholecystectomy.
\end{abstract}

Keywords: Abscess, Dissection, Gallstones, Laparoscopic Cholecystectomy, Liver.

\section{Introduction}

Laparoscopic cholecystectomy is surgery of choice for gallstones but it is not free of complications. Training skills and experience can minimize these complications [1,2]. Spillage of gallstone occurs less frequently and is ignored most of the time. Spillage can occur during dissection of gallbladder from liver bed, injury to the gallbladder wall from grasping forceps and during removal of gallbladder from port site $[3,4]$. These are more common in inflamed and friable gallbladder [3,4]. Spilled stones left in peritoneum and abdominal wall rarely causes clinically significant complications but it may increase morbidity [1]. We are presenting a case of 52 years male who presented with discharging sinus from epigastric port site scar after laparoscopic cholecystectomy. Whole sinus tract was excised and wound was primary closed.

\section{Case Report}

A 52 years male presented with discharging sinus for 10 days from a scar of epigastric port site of laparoscopic cholecystectomy. He had undergone laparoscopic cholecystectomy six months ago. His immediate post-operative period was uneventful. He developed pain at epigastric port site scar followed by pustular eruption which ruptured with purulent discharge. He was started on antibiotics. Pain and discharge decreased but did not disappear completely. On local examination, a sinus tract was present over old surgical scar of epigastric port site. Sinus tract showed thin watery discharge without any signs of local inflammation.

Hematological examination was within normal limit. Ultrasonography of abdominal wall showed a sinus tract with $2 \mathrm{ml}$ collection in anterior abdominal wall without any communication to peritoneal cavity. Sinogram showed a $3.5 \mathrm{~cm}$ long sinus tract which was extending posteriorly without any communication to peritoneal cavity [Fig.1].

Excision of sinus tract was done under local anaesthesia. A horizontal elliptical incision was given, subcutaneous tissue incised and whole sinus tract was excised upto pre-peritoneal space [Fig.2]. After securing hemostasis wound was primarily closed. Post operative period was uneventful. Cut 
section of sinus tract showed spilled gallstone [Fig.3].

\section{Discussion}

Most common disorder of gallbladder and biliary tract is gallstone and laparoscopic cholecystectomy is the gold standard operation for symptomatic gallstones [1,2]. Laparoscopic cholecystectomy has several advantage over traditional approach but spillage of bile and gallstones are more common [4-6]. Spillage can occur during dissection of gallbladder from liver bed, injury of gallbladder wall from traction by grasping forceps and during removal of gallbladder from port site $[1,6]$. These are more common in inflamed and friable gallbladder $[1,6]$. These spilled stones rarely cause any significant problems but in some cases require active intervention and increase morbidity. Intraabdominal abscesses, adhesions, cutaneous sinus and fistula are the common complications by spilled stones [3]. These infective complications are mainly by pigmented gall stones $[3,6]$.

Complications can be best prevented by prevention of spillage of stones, aspiration of distended and tense gall bladder can be done before dissection to minimize chances of perforation [2]. Traction by grasping forceps should be gentle to minimize perforation of gall bladder. Correct plane identification between the gall bladder and surrounding structures and meticulous dissection are necessary to prevent perforation of gallbladder and spillage [2]. In case of perforation, spillage can be controlled by placing an endo-loop or clips over the area or by placing the grasper in such a way as to close the perforation. These techniques may prevent stones from falling out during the rest of the dissection. Peritoneal cavity should be washed with saline to dilute the infected bile and all possible efforts should be made to retrieve the lost stones after spillage [2,6]. Gallbladder should ideally be taken out from the epigastric or umbilical port under camera vision so that spillage can be easily recognized. Fascial incision should

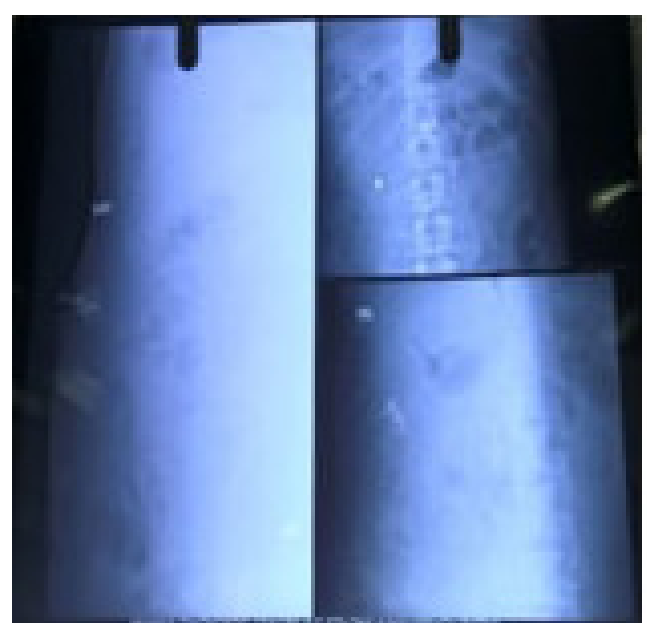

Fig.1: Sinogram showing sinus tract.

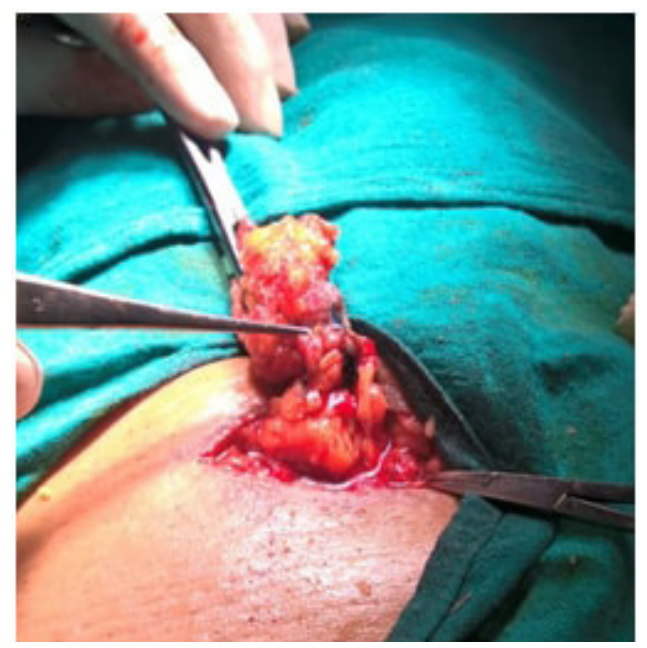

Fig.2: Intra-operative picture of sinus tract.

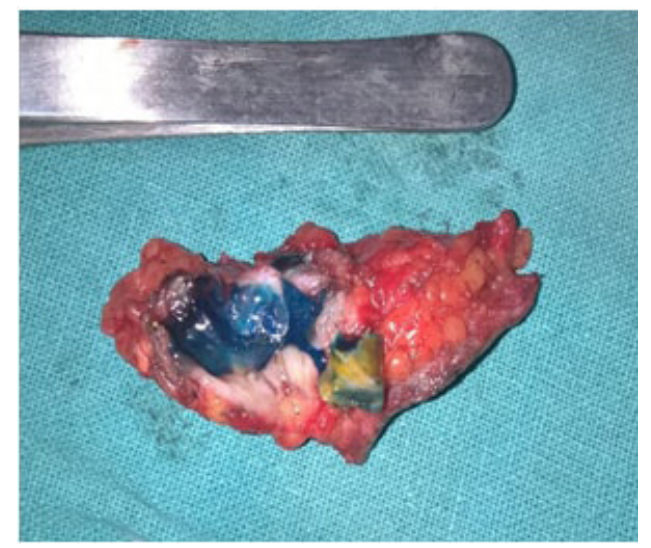

Fig.3: Cut section of sinus tract showing spilled gallstone. 
be easily extended for the large stones. Suction of the gallbladder can be done to reduce its size, and the stones can be removed with a ring or ovum forceps. The gallbladder can also be placed in a sterile bag for removal [2].

Spilled gallstone should not be avoided and its removal should be considered seriously even if operative time is increased. Several devices like spoon, disposable bag or sleeve, large shuttle collector facilitate this process [2]. These complications should be mentioned in patients documents and patients should be follow-up regularly [2].

\section{Conclusion}

Spillage is uncommon problem in laparoscopic cholecystectomy but it may lead to significant problem in some cases. A high index of suspicion regarding spilled stone should be kept in mind in a patient presenting with port site sinus after laparoscopic cholecystectomy.

Contributors: AH: manuscript writing, patient management; VK: manuscript editing, patient management; $\mathrm{AH}$ will act as guarantor. Both authors approved the final version of this manuscript.

Funding: None; Competing interests: None stated.

\section{References}

1. Schafer M, Suter C, Klaiber C, Wehrli H, Frei E, Krähenbühl L. Spilled gallstones after laparoscopic cholecystectomy. A relevant problem? A retrospective analysis of 10,174 laparoscopic cholecystectomies. Surg Endosc.1998;12:291-293.

2. Khalid Husain K, Tara AM, Waha MS, Mian AM, Masood J. Parietolith: A late complication of spilled gallstones. Journal of the College of Physicians and Surgeons Pakistan. 2015;25:s91-s92.

3. Memon MA, Deeik RK, Maffi TR, Fitzgibbons RJ Jr. The outcome of unretrieved gallstones in the peritoneal cavity during laparoscopic cholecstectomy. A prospective analysis. Surg Endosc. 1999;13:848-857.

4. Tschmelitsch J, Glaser K, Klingler A, Klingler P, Bodner E. Late complication caused by stone spillage during laparoscopic cholecystectomy [letter]. Lancet 1993;342:369.

5. Chrungoo RK, Mala TA, Singh G, Mohan S, Mala SA, Kumar A. Parietolith; Uncommon but preventable complication of gallstone spillage after laparoscopic cholecystectomy. IOSR Journal of Dental and Medical Sciences. 2013;6:54-56.

6. Kumar TS, Saklani AP, Vinayagam R, Blackett RL. Spilled gall stones during laparoscopic cholecystectomy: a review of the literature. Postgrad Med J. 2004:80:7779. 